\title{
Digital capabilities: from niche to normal
}

\section{Andy White}

Cumbria University

Amanda Chapman

Cumbria University

Isabel Lucas

Cumbria University

Keywords: Digital transformation; staff development; Covid -19.

\section{The challenge}

Although a digital capabilities strand, based on the Jisc Digital Capabilities Framework (Jisc, 2015), had recently been started at the University, many staff had not engaged with the digital agenda and did not have sufficient skills to move their practice online at the point of lockdown. The vast majority of University business was campus-based, with only three pure distance learning degrees out of 330 taught degrees. The Jisc framework highlights the skills needed to help staff flourish in a digital environment; however, given the rural nature of our campuses and the lack of success in engaging tutors with distance/online learning, we experienced additional challenges involving connectivity and digital resistance.

The overall aim of the project was to digitally-enable staff without overwhelming them by prescribing a core set of technology, along with a set of guiding principles and minimum standards for their use. Taking this approach, the result expected was that more digitally resistant staff would have a realistic baseline to work with which could be readilysupported by the Academic Development Centre and which would provide a good student experience. For more digitally confident tutors, we hoped it would provide space and support to develop their digital practice beyond the minimum expectations. 


\section{The response}

At the Academic Development Centre we moved quickly in March 2020, developing clear expectations for Blended Learning as our first step and producing a Guiding Principles and Expectations document with suggestions, tips, checklists for teams, and student facing templates (e.g., Module Learning Plan template that made clear what was a/synchronous, expected hours of learning per activity etc).

Our initial rationale was to keep things simple to not overwhelm. Online tools, such as Blackboard and PebblePad, had been used to support delivery on, and between, campuses for a number of years, however it was clear some staff felt the need to use a wide range of 'digital tricks' to make up for the perceived deficit of online learning. The second step was to streamline the technology options for tutors to ensure that the students had consistency of experience and that tutors could develop their online teaching rather than worry about the 'right' technology. A new online classroom platform, Collaborate, was purchased from our existing VLE provider so some familiarity with the technology was embedded.

CPD activity was accelerated with a $220 \%$ increase in attendance in the four months of March - June. Further, the Annual Teaching and Learning Conference drew on tutors with previous online teaching and/or learning experience to share their approaches and motivate colleagues. This was the necessary third step to support understanding of expectations. The CPD we offered had a 3-fold approach: how to use the new live classroom, how to develop pre-recorded material, and how to engage students in this new online world.

\section{Recommendations}

The success of this institutional shift hinges on what is retained and carried forward: the digital transformation maturity (Marks et al., 2021). Some practices have improved during the pandemic and we recognise the need to ensure that staff make continued use of their digital expertise and confidence going forward. 
Among many successes this had led to the vast majority of tutors stating that their confidence in their own digital-based activities to support different learning outcomes has increased by 25 percentage points in the space of a year. The same group of tutors state that their confidence in supporting their students' digital capabilities has increased by 14 percentage points. A senior colleague has stated that the Centre is now a "trusted brand" and this is further supported by tutors and senior management who have applauded the approach and the support from the Academic Development Centre which lays a stronger foundation for moving forward at pace with the digital agenda.

Key lessons learnt through this project are:

- Have clear, achievable expectations which tutors at any digital level can work with; use a variety of modes to get this out to tutors. Use in-house tutor expertise to help produce these expectations so you have champions distributed across the organisation.

- Engage senior management to ensure an institution-wide approach that can easily be communicated vertically and horizontally and with students. This facilitated greater collaborative working, in particular with IT and Student Services (we are reaping the rewards of that strengthened relationship now with new initiatives that previously would have taken longer to launch).

- Use CPD to weave in related good practice and requirements. The university as a whole had been building up to meeting the changes to the Web Accessibility Directive (Gov.uk, 2018) in September 2020; we incorporated this into the move to online delivery so as not to lose pace.

- Incorporate regular feedback from stakeholders to capture areas of need and to ensure you can report on impact. For example, we provided CPD sessions called 'Going slowly with...' to nurture the digitally resistant staff by taking them slowly through a specific process step-by-step. We also regularly benchmark a randomised sample of Blackboard sites to inform our on-going CPD plan, check accessibility and to reward teams.

- Reward teams; recognise good practice and feed this back and upwards.

The digital upskilling of staff was already part of our five-year plan but we had struggled with the digitally-resistant (Newland and Handley, 2016; Chambers, McKinney and 
Schmid, 2018). The pandemic accelerated this plan and brought about tangible institutional change (Tesar, 2020).

Going forward we are less prescriptive of the platforms that staff can use with evidencebased decisions made at the programme or subject level. Having effective, embedded, accessible, digital delivery and assessment across the curriculum, with staff actively participating, would have seemed a longer-term ambition at the start of 2020 but nearly 18 months on what would have seemed 'niche' at the start of 2020 is now becoming 'normal'.

\section{References}

Chambers R., McKinney R., Schmid M., Beaney P., (2018) 'Digital by choice: becoming part of a digitally ready general practice team', Primary Health Care, 28(7), pp1-6. DOI: https:// doi.10.7748/phc.2018.e1502

Gov.uk, Understanding accessibility requirements for public sector bodies. Available at: https://www.gov.uk/guidance/accessibility-requirements-for-public-sector-websitesand-apps (Accessed: 12 July 2021).

Jisc, Digital Capabilities Framework (2015). Available at:

https://www.digitalcapability.jisc.ac.uk/what-is-digital-capability/individual-digitalcapabilities/our-digital-capabilities-framework/ (Accessed: 8 June 2021).

Marks, A., AL-Ali, M., Attasi, R., Elkishk, A. A. and Rezgui, Y. (2021) 'Digital transformation in higher education: maturity and challenges post COVID-19', pp.1-10, in Rocha, Á., Ferrás, C., López-López, P. C. and Guarda, T. (eds.) Information Technology and Systems. ICITS 2021. Advances in Intelligent Systems and Computing, 1330. Cham: Springer.

Newland, B. and Handley, F. (2016) 'Developing the digital literacies of academic staff: an institutional approach', Research in Learning Technology, 240. DOI: https://doi.org/10.3402/rlt.v24.31501 
Tesar, M (2020) 'Towards a post-Covid-19 "new normality"? Physical to social distancing, the move to online and higher education', Policy Futures in Education, 18(5), pp.556559. DOI: https://doi.org/10.1177/1478210320935671

\section{Author details}

Andy White is the Learning Technologies Manager in the Centre for Academic Practice Enhancement at the University of Cumbria, UK. He has strategic oversight of core platforms and responsibility for digital skill development for academic tutors. He has over 20 years' experience in HE and is a Senior Fellow of AHE.

Amanda Chapman is a Senior Academic Developer in the Centre for Academic Practice Enhancement at the University of Cumbria, UK. She is Programme Leader for the PgCert Learning and Teaching in Higher Education and Scheme Lead for AdvanceHE Fellowships.

Isabel Lucas is the Head of Centre for Academic Practice Enhancement at the University of Cumbria, UK. She has taught in the UK and overseas for over 25 years, holds a number of external roles related to Learning, Teaching and Quality Enhancement and is a Senior Fellow (AHE). 